Original Article

\title{
Survey report on awareness and participation behavior in disabled sports and disability understanding after Tokyo's bid for the 2020 Olympics and Paralympics
}

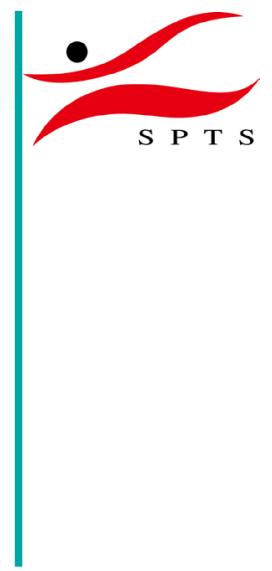

\author{
Котомі Sнiота, RPT, $\mathrm{PhD}^{1,2)}$ \\ 1) Organization for University Research Initiatives, Waseda University: 1-6-1 Nishiwaseda, \\ Shinjuku-ku, Tokyo 169-8050, Japan \\ 2) Institute of Health and Community Sports, Japan
}

\begin{abstract}
Purpose] This study analyzes awareness and participation behavior in disabled sports and disability understanding after Tokyo's bid for the 2020 Olympics and Paralympics. [Subjects and Methods] The study conducted a cross survey on 220 registrants of an Internet research firm. It analyzed: the awareness of citizens and their behavioral changes, in the aftermath of the allocation of Olympic and Paralympic Games; subject attributes and education level; recognition of disabled sports; and the awareness and behavior of participants, with regard to disabled sports. The analysis was conducted using SPSS Ver. 21 (IBM). [Results] The subjects were not interested in watching $(72.2 \%)$, participating $(76.8 \%)$, or volunteering $(71.8 \%)$ in disabled sports. In addition, $76.8 \%$ of the subjects exhibited no behavioral changes - such as by watching, participating, or volunteering in disabled sportsafter the Olympics and Paralympics bid decision. [Conclusion] This study's subjects had no confidence in their disability knowledge and no opportunities to interact with disabled persons. Furthermore, the bids for mega-events such as the Olympic and Paralympic Games did not lead to behavioral changes concerning disabled sports. Therefore, disability understanding should promote and deepen participation behavior in disabled sports.

Key words: Paralympic games, Disabled sports, Disability understanding
\end{abstract}

(This article was submitted Jul. 18, 2017, and was accepted Oct. 4, 2017)

\section{INTRODUCTION}

Although the 2020 Tokyo Olympic and Paralympic bids have been decided, challenges abound, especially for the disabled sports of the Paralympic Games. One important issue is that human resources (i.e., participation) for the "watch," "play," and "support" aspects of disabled sports are insufficient. Mega-events such as the Paralympics should draw the attention of the entire nation. In terms of the "watch" factor, however, many of the competitions involving people with disabilities can be watched for free, but only by family and sports officials. The general audience for such events is small. In addition, the Internet audience for disabled sports in Japan is less than half that in other countries ${ }^{1)}$. In terms of the "play" factor, many people interested in disabled sports are also interested in conventional sports. Recently, schools have begun exposing students to disabled sports ${ }^{2}$. However, though some local competitions have drawn more abled audiences, voluntary participation has not increased. In terms of "support," many volunteers are required to care for and help disabled players and management. However, disabled sports are run by a small group of personnel, such as teachers, school staff, and family. Personnel shortages are chronic. In addition, a mere $8.3 \%$ of volunteers wish to assist with the Paralympic Games ${ }^{3)}$.

Previous study $\left.{ }^{4}\right)$ that participants were not interested in watching $(61.3 \%)$, participating (66.9\%), or volunteering $(66.1 \%)$ 
in disabled sports, indicating low awareness and interest among the general public. In addition, $43.2 \%$ of the subjects had no direct experience with disabled people. Japanese have little opportunity to engage with the disabled unless one is a professional who deals with people with disabilities. Given this social and cultural background, changing the abled community's participation behavior in disabled sports will require transforming their attitudes about people with disabilities, through a "disability understanding." This in turn requires the promotion of participation in disabled sports among the abled. Tokyo's bid for the 2020 Olympics and Paralympics was an opportunity to address the environment surrounding the disabled. Barriers must be removed through understanding and knowledge. Disabled sports has an important role to play in that process.

The Paralympics held in London in 2012 witnessed the highest number of tickets sold in the history of the Paralympic Games ${ }^{5)}$. Therefore, it is considered to be a successful model that can be emulated by other cities hosting the Paralympics. The success of Paralympic Games is critically dependent on promoting the understanding of disabilities among citizens ${ }^{5)}$. In addition, it is reported that the rate of participation in regular physical activity (including exercise and sports) by persons with disabilities in the community is extremely low ${ }^{6}$. There is a need in the community for creating an environment in which patients returning to their homes can maintain a physical activity routine. However, the participation rate of disabled persons in sports events held in the community is low ${ }^{3}$. Therefore, public understanding and support are necessary to expand the opportunity set of activities open to persons with disabilities. Thus, it is necessary to understand the perception about participation behavior in disabled sports, based on factors related to the public understanding of disability. In addition, it is urgent to consider that approach. This research has positioned itself as a basic investigation. Its purpose is to analyze the level of awareness in Japan about disabled sports, participation behavior in them, and disability understanding among citizens, in the context of Tokyo's successful bid for the 2020 Olympics and Paralympics.

\section{SUBJECTS AND METHODS}

This study obtained the approval of the ethics committee of Waseda University (2014-197). The subjects were registered at an Internet company. The subjects answered the survey items in March 2015 after providing their consent.

This study conducted a 5-day cross survey from March 19th to 23rd, 2015. This survey was entrusted to an internet survey company (Company A; it had 1.2 million registrants and the monitor was registered with it). The Internet survey provides the advantage of being able to conduct a large-scale survey; however, an associated drawback is that it returns a biased sample of highly educated and high-income people respondents. In order to eliminate these influences in the survey, it was decided to create the following 5 "layers" of 40 males and females each: those in their 20s; 30s; 40s; 50s; and 60s. Thus, the aim was to target 200 or more respondents from different regions in Japan. In addition, the annual income is considered to be more highly relevant, when compared with other attributes such as academic background; focusing on the income attribute ${ }^{7}$, the Internet survey company selected those with an annual income greater than 5,720,000 yen from the results of the Family Income and Expenditure Survey 2014 ${ }^{8}$. The company created the survey based on the investigation specifications provided by the researchers and sent an email containing a link to the online survey screen. Company A made assignment based on the contents of the request and investigated by e-mail attached a link to the survey screen to 696 subjects randomly extracted for the monitor. The email included the purpose of this survey and informed respondents of their freedom to participate, as well as the fact that their privacy and anonymity would be strictly preserved; if the respondents' consent is obtained, they are taken to the investigation screen, where they can respond to the survey questions. It was decided that extra responses should be collected to take care of invalid responses and a survey size of 220 (i.e., 110\% of the target sample) was chosen. The survey was terminated when 231 responses, including more than 40 responses for each layer, were received. The response rate was $33.2 \%$. Out of the 231 respondents, 11 did not obtain consent for the investigation and were excluded. The data of the remaining 220 people were screened for missing or abnormal answers. Although there are several methods for processing missing values in investigation research, it is said that bias is less likely to occur when the values are missing at random. Therefore, in this research, it was confirmed that the responses had no missing entries; further, it was also checked that consecutive questions were not left unanswered when omissions in individual answer items were found. The unanswered items were processed as missing data. As a result, 220 subjects were analyzed in this study.

The subject attributes used in the study include the subjects' place of residence, gender, age, marital status, occupation, education level, household income, newspaper subscriptions, duration of television viewing, and duration of internet use (Table 1).

To assess the respondents awareness of and behavior concerning disabled sports, the survey measured their "watching behavior" concerning disabled sports (including on TV and the Internet), their "participant behavior" during disabled sports events, and their "volunteer behavior" on 5-points scales (i.e., "Done continuously," "Occasionally done," "Willing to do in the future," "Not thinking about acting in the future," and "Not interested").

The change in the awareness about disabled sports before the 2020 Tokyo Olympic and Paralympic Games bid decision and that after it was measured by using several items as follows. Respondents answered on a 5-point scale from "More interested" to "No longer interested." Behavioral changes among spectators of disabled sports (including on TV and the Internet) were measured via the "watching behavioral change" item. The "participation behavioral changes" item measured participation in disabled sports activities. Disabled sports volunteerism was measured via the "volunteer" item, and the "information behavior change" item measured respondents" desire for information about disabled sports. Multiple answers were allowed. 
As regards the awareness about disabled sports, the following views were elicited from respondents: whether people with disabilities can play sports; whether disabled sports are meaningful ("need"), dangerous ("risk"), or simple ("ease"). Respondents were also asked about disabled sports personalities ("playability") and whether the disabled and abled can play sports together ("symbiosis"). All items were answered on a 5-point scale from "I do not think so at all" to "I agree very much." In addition, direct experience with people with disabilities was measured on a 5-point scale, from "Very positive" to "Very negative."

The respondents' knowledge about disabilities was gauged as follows: methods of learning about disabilities (i.e., in school, professionally, self-taught, never studied, and other) were reported using five items, permitting multiple answers. Respondents indicated their confidence in their knowledge of disabilities, from "no confidence" to "I have confidence" (four items).

Methods of analysis is that frequencies and percentages were calculated by scoring the 220 valid responses. Analysis was conducted based on the descriptive statistics using SPSS Ver. 21 (IBM).

\section{RESULTS}

The results relating to subject attributes shown in Table 1 are as follows: of the 220 respondents (112 males, 108 females, of an average age of 44.9 [ \pm 15.0 years] $), 13.6 \%$ were males in their $50 \mathrm{~s}$, the highest proportion; $12.7 \%$ were women in their $20 \mathrm{~s} ; 12.4 \%$ were women in their $30 \mathrm{~s}$; and $11.8 \%$ were women in their $40 \mathrm{~s}$. The men's ages were widely dispersed, but most women were between 20 and 40. Disabled people did not participate in this survey. Non-residents of Tokyo comprised $18.1 \%$ of the sample. The sample was split almost evenly between married and unmarried respondents. Office workers comprised $40.5 \%$ of the sample, housewives and househusbands $14.1 \%$, the unemployed $14.5 \%$, the irregularly employed $12.3 \%$, and students $6.4 \%$. A total of $30.5 \%$ of the sample had household annual incomes of between 300 and 500 thousand yen, 18.2\% had between 300 and 500 thousand yen, and $25.9 \%$ had between 500 and 700 thousand yen, and the approximate average annual household income. The subjects of this study were mostly young urban women, with no other specific characteristics ${ }^{8,9)}$.

The behavioral characteristics of respondents that were analyzed are as follows: education, awareness of disabled sports, awareness and behavior change after the Olympics and Paralympics decision, and awareness and behavior concerning disabled sports were scored using the 220 valid responses. Average values and standard deviations are shown in Tables 2 to 3 . The subjects were not interested in watching $(72.2 \%)$, participating $(76.8 \%)$, or volunteering $(71.8 \%)$ in disabled sports. On the other hand, $90 \%$ of subjects saw a need for sports for people with disabilities. $76.8 \%$ of respondents experienced no behavioral changes - such as by watching, participating, or volunteering in disabled sports - after the 2020 Tokyo Olympics and Paralympics decision. The greatest change, $15.5 \%$, was in seeking information. Only $1.4 \%$ of subjects participated as a volunteer.

In addition, the proportion of subjects with favorable direct experiences of the disabled was equal to those with negative experiences. Furthermore, $68.6 \%$ had no educational experience concerning disabilities, and $84.6 \%$ had "No confidence" in their knowledge of disabilities.
Table 1. Subject attributes

\begin{tabular}{|c|c|c|}
\hline & Persons & $\%$ \\
\hline \multicolumn{3}{|l|}{ Male } \\
\hline $20 \mathrm{~s}$ & 15 & 6.8 \\
\hline $30 \mathrm{~s}$ & 18 & 8.1 \\
\hline $40 \mathrm{~s}$ & 18 & 8.1 \\
\hline $50 \mathrm{~s}$ & 30 & 13.6 \\
\hline $60 \mathrm{~s}$ & 19 & 8.6 \\
\hline $70 \mathrm{~s}$ & 12 & 5.4 \\
\hline \multicolumn{3}{|l|}{ Female } \\
\hline $10 \mathrm{~s}$ & 1 & 0.5 \\
\hline $20 \mathrm{~s}$ & 28 & 12.7 \\
\hline $30 \mathrm{~s}$ & 26 & 11.8 \\
\hline $40 \mathrm{~s}$ & 26 & 11.8 \\
\hline $50 \mathrm{~s}$ & 14 & 6.3 \\
\hline $60 \mathrm{~s}$ & 12 & 5.4 \\
\hline $70 \mathrm{~s}$ & 1 & 0.5 \\
\hline \multicolumn{3}{|l|}{ Residential areas } \\
\hline Tokyo & 40 & 18.1 \\
\hline Other & 180 & 81.9 \\
\hline \multicolumn{3}{|l|}{ Work area } \\
\hline Tokyo & 50 & 22.6 \\
\hline Other & 170 & 77.4 \\
\hline \multicolumn{3}{|l|}{ Marital status } \\
\hline Married & 96 & 43.6 \\
\hline Unmarried & 124 & 56.4 \\
\hline \multicolumn{3}{|l|}{ Education } \\
\hline Graduate school & 12 & 5.5 \\
\hline University & 108 & 49.1 \\
\hline Junior college & 18 & 8.2 \\
\hline Vocational school & 21 & 9.5 \\
\hline High school & 58 & 26.4 \\
\hline Junior school & 1 & 0.5 \\
\hline Other & 2 & 0.9 \\
\hline \multicolumn{3}{|c|}{ Occupational classification } \\
\hline Company employee & 89 & 40.5 \\
\hline Self-employed & 12 & 5.5 \\
\hline Professional & 4 & 1.8 \\
\hline Civil service & 8 & 3.6 \\
\hline Student & 14 & 6.4 \\
\hline Full-time housewife & 31 & 14.1 \\
\hline Part-time job & 27 & 12.3 \\
\hline Unemployed & 32 & 14.5 \\
\hline Other & 3 & 1.4 \\
\hline \multicolumn{3}{|c|}{ Income (ten thousand yen) } \\
\hline less than 300 & 40 & 18.2 \\
\hline $300-500$ & 67 & 30.5 \\
\hline $500-700$ & 57 & 25.9 \\
\hline $700-1,000$ & 32 & 14.5 \\
\hline $1,000-1,500$ & 20 & 9.1 \\
\hline Over 1,500 & 4 & 1.8 \\
\hline \multicolumn{3}{|l|}{ TV viewing time } \\
\hline $30 \mathrm{~min}-1 \mathrm{~h}$ & 41 & 18.6 \\
\hline $1 \mathrm{~h}-2 \mathrm{~h}$ & 63 & 28.6 \\
\hline $2 \mathrm{~h}-3 \mathrm{~h}$ & 41 & 18.6 \\
\hline $3 h-4 h$ & 31 & 14.1 \\
\hline Over $4 \mathrm{~h}$ & 38 & 17.2 \\
\hline Not on weekdays & 6 & 2.7 \\
\hline \multicolumn{3}{|l|}{ Internet use time } \\
\hline $30 \mathrm{~min}-1 \mathrm{~h}$ & 27 & 12.3 \\
\hline $1 \mathrm{~h}-2 \mathrm{~h}$ & 72 & 32.8 \\
\hline $2 \mathrm{~h}-3 \mathrm{~h}$ & 47 & 21.4 \\
\hline $3 \mathrm{~h}-4 \mathrm{~h}$ & 23 & 10.5 \\
\hline Over $4 \mathrm{~h}$ & 49 & 22.3 \\
\hline Not on weekdays & 2 & 0.9 \\
\hline
\end{tabular}


Table 2. The awareness of disabled sports participation and attitude

\begin{tabular}{lrr}
\hline & Persons & $\%$ \\
\hline Awareness of and befavior concerning disabled sports & & \\
Awareness and attitude of spectators of disability sport (watching behavior) & 2 & 0.9 \\
Done continuously & 16 & 7.3 \\
Occasionally done & 43 & 19.5 \\
Willing to in the future & 63 & 28.6 \\
Not thinking of acting in the future & 96 & 43.6 \\
Not interested & 2 & 0.9 \\
Awareness and attitude concerning event participation and experience (participant behavior) & 2.7 \\
Done continuously & 6 & 19.5 \\
Occasionally done & 43 & 30.0 \\
Willing to in the future & 66 & 46.8 \\
Not thinking of acting in the future & 103 \\
Not interested & 2 & 0.9 \\
Awareness and attitude concerning disabled sports volunteering (volunteer behavior) & 9 & 4.1 \\
Done continuously & 51 & 23.2 \\
Occasionally done & 57 & 25.9 \\
Willing to in the future & 101 & 45.9 \\
Not thinking of acting in the future & & \\
Not interested & & \\
Before and after the 2020 Tokyo Olympic and Paralympic Games bid decision & 11 & 5.0 \\
Consciousness change after the Olympics and Paralympics & 49 & 22.3 \\
More interested & 153 & 69.5 \\
Interested & 1 & 0.5 \\
Neither agree nor disagree & 6 & 2.7 \\
Not interested & & \\
Less interested & 12 & 5.5 \\
Behavioral changes after the Olympics and Paralympics & 8 \\
Watching & 3 & 3.6 \\
Participating in the event & 34 & 1.4 \\
Volunteering & 169 & 76.8 \\
Getting information & & \\
No change in behavior & & \\
\hline
\end{tabular}

\section{DISCUSSION}

$76.8 \%$ of the sample exhibited no behavioral changes - such as by watching, participating, or volunteering in disabled sports - after the Olympics and Paralympics bid decision. This shows that mega-events such as the Paralympic Games have little effect on the behavioral changes of the general public.

According to Mullin et al. ${ }^{10)}$ consumption behavior in sports, including decision-making about sports participation and spectatorship, is influenced by environmental and personal factors such as "socialization," "involvement," and "commitment." The authors also argue that the process of socialization involves gaining increased awareness of and attracting interest in sports, as well as arousing a desire and initiating action regarding it.

The Tokyo Olympic and Paralympic Games decision provided a strong awareness of disabled sports. In their previous study, the authors found a 99\% awareness of the Paralympic Games, and awareness of Japan's Paralympics was high relative to other countries ${ }^{1)}$. In this study, however, only $27.3 \%$ of subjects reported increased interest in the Paralympics after the bid decision, and $80 \%$ reported no change in behavior such as volunteering. Only $20 \%$ admitted behavioral changes, and $15.5 \%$ of them only sought information, which does not represent a real change in behavior. Items on the "necessity" of disabled sports, the recognition of disabled athletes ("playability"), "need," and sports symbiosis had high values (70\%). Respondents considered disabled sports to be an authentic genre of sport. While the "necessity" of disabled sports had a high value, "ease" did not. Concerning knowledge, $68.6 \%$ of the sample had never studied disabilities, and $84.6 \%$ reported having no confidence in their knowledge of it. In addition, the proportion of subjects with favorable direct experiences of the disabled was equal to those with negative experiences.

This study's subjects had no confidence in their disability knowledge and no opportunity to interact with disabled persons. Previous research reported that cooperation between the disabled and abled in the playing of disabled sports has positive effects on disability understanding ${ }^{11-15)}$. Therefore, disability understanding should promote and deepen participation behavior in disabled sports. It is also important to engage in positive behavior. It is reported that a significant problem preventing the participation in sports of persons with disabilities is the near absence of influencers with knowledge of disability. This study revealed that the citizens had limited contact experience with disabled people and little confidence in their knowledge about disability. To alleviate this in the future, it is essential that medical personnel become facilitators in the promotion of physical 
Table 3. Educational experience of disabled and recognition of disabled sport

\begin{tabular}{|c|c|c|}
\hline & Persons & $\%$ \\
\hline \multicolumn{3}{|l|}{ Awareness of disabled sport } \\
\hline \multicolumn{3}{|c|}{ I think disable sports are meaningful (need) } \\
\hline Very much so & 98 & 44.5 \\
\hline Somewhat so & 77 & 35.0 \\
\hline Neither agree nor disagree & 39 & 17.7 \\
\hline I do not think so & 5 & 2.3 \\
\hline I do not think so at all & 1 & 0.5 \\
\hline \multicolumn{3}{|c|}{ I think people with disabilities can do sports that are dangerous (risk) } \\
\hline Very much so & 6 & 2.7 \\
\hline Somewhat so & 51 & 23.2 \\
\hline Neither agree nor disagree & 93 & 42.3 \\
\hline I do not think so & 59 & 26.8 \\
\hline I do not think so at all & 11 & 5.0 \\
\hline \multicolumn{3}{|c|}{ I think people with disabilities can do sports that are easy (easy) } \\
\hline Very much so & 4 & 1.8 \\
\hline Somewhat so & 15 & 6.8 \\
\hline Neither agree nor disagree & 47 & 21.4 \\
\hline I do not think so & 92 & 41.8 \\
\hline I do not think so at all & 62 & 28.2 \\
\hline \multicolumn{3}{|c|}{ I think disabled sports have athlete personalities (playablity) } \\
\hline Very much so & 111 & 50.5 \\
\hline Somewhat so & 68 & 30.9 \\
\hline Neither agree nor disagree & 35 & 15.9 \\
\hline I do not think so & 4 & 1.8 \\
\hline I do not think so at all & 2 & 0.9 \\
\hline \multicolumn{3}{|c|}{ I think disabled sports can be played with the abled (symbiosis) } \\
\hline Very much so & 34 & 15.5 \\
\hline Somewhat so & 74 & 33.6 \\
\hline Neither agree nor disagree & 91 & 41.4 \\
\hline I do not think so & 16 & 7.3 \\
\hline I do not think so at all & 5 & 2.3 \\
\hline \multicolumn{3}{|c|}{ The image of those who are in contact with disability } \\
\hline Favorable impression & 23 & 10.5 \\
\hline Little favorable impression & 24 & 10.9 \\
\hline No impression & 60 & 27.3 \\
\hline Small negative impression & 5 & 2.3 \\
\hline Very negative impression & 3 & 1.4 \\
\hline \multicolumn{3}{|l|}{ Knowledge of disablities } \\
\hline \multicolumn{3}{|c|}{ The learning experience for disability } \\
\hline School education & 33 & 15.0 \\
\hline Professional learning & 15 & 6.8 \\
\hline Self-education & 21 & 9.5 \\
\hline No study & 151 & 68.6 \\
\hline \multicolumn{3}{|c|}{ Confidence in knowledge of disability } \\
\hline Confident & 4 & 1.8 \\
\hline A little confidence & 30 & 13.6 \\
\hline Not much confidence & 93 & 42.3 \\
\hline Unconfident & 93 & 42.3 \\
\hline
\end{tabular}

activity for persons with disabilities in their areas of operation. They can do so by teaching appropriate support methods, including disability understanding. In addition, the holding of the Tokyo Olympic and Paralympic Games in 2020 is not just an event; it is necessary to convert it into a timely opportunity to try and improve the environment for persons with disabilities.

\section{REFERENCES}

1) The Nippon Foundation's Research Group on the Paralympics: 2014. Survey on the general public's awareness and interest in the Paralympics in Japan and in some selected countries. http://para.tokyo/english/doc/survey201411.pdf (Accessed Jun. 26, 2017)

2) Obrusníková I, Valkova H, Block ME: Impact of inclusion in general physical education on students without disabilities. Adapt Phys Activ Q, 2003, 20: 230-245. [CrossRef]

3) Ono K: The 2014 SSF National Sports-Life Survey. Tokyo: Sasakawa Sports Foundation, 2014, pp 95-99. 
4) Shiota K, Tokui A: Factors affecting volunteer participation in sport for the disabled. Jpn J Phys Educ Hlth Sport Sci, 2016, 61: 149-158. [CrossRef]

5) NHK Online: 2014. http://www.nhk.or.jp/shutoken/miraima/articles/00050.html (Accessed Jun. 26, 2017)

6) Shiota K, Tokui A: The fundamental study for understanding of the recreation and sports in disabled children of school for special needs. J Jpn Health Sci, 2016, 19: 1-9.

7) Schmidt W: World-Wide Web survey research: Benefits, potential problems, and solutions. Behav Res Methods Instrum Comput, 1997, 29: 274-279. [CrossRef]

8) Statistics Bureau: Family Income and Expenditure Survey 2014. http://www.stat.go.jp/data/index.htm. (Accessed Jun. 26, 2017)

9) Ministry of Health, Labour and Welfare: Labour surveys 2014. http://www.mhlw.go.jp/toukei/saikin/hw/k-tyosa/k-tyosa14/d1/16.pdf. (Accessed Jun. 26, 2017)

10) Mullin BJ, Hardy S, Sutton WA: Sport Marketing. Human Kinetics Publishers, 2007, pp 1-552.

11) Donaldson J: Channel variations and effects on attitudes toward physically disabled individuals. Av Communica Rev, 1976, 24: 135-144.

12) Nakamura Y: Realization of "Shougai" with knowledge and contact. Bulletin of the School of Education. Bukkyo Univ, 2011, 10: 1-10.

13) Tripp A, French R, Sherrill C: Contact theory and attitudes of children in physical education programs toward peers with disabilities. Adapt Phys Activ Q, 1995, 12: 323-332. [CrossRef]

14) Tabiki T: Research on participation motive of volunteers who support sports for the people with disabilities. J Med Welf, 2008 , 4: 98-107.

15) Fujita K, Fujiwara Y, Kumagai S, et al.: [The frequency of going outdoors, and physical, psychological and social functioning among community-dwelling older adults]. Nippon Koshu Eisei Zasshi, 2004, 51: 168-180. [Medline] 